\title{
Glipizide, an antidiabetic drug, suppresses tumor growth and metastasis by inhibiting angiogenesis
}

\author{
Cuiling Qi ${ }^{1, *}$, Qin Zhou ${ }^{1, *}$, Bin Li ${ }^{1}$, Yang Yang ${ }^{1}$, Liu Cao ${ }^{4}$, Yuxiang Ye ${ }^{1}$, Jiangchao \\ $\mathbf{L i}^{1}$, Yi Ding ${ }^{1}$, Huiping Wang ${ }^{1}$, Jintao Wang ${ }^{1}$, Xiaodong He ${ }^{1}$, Qianqian Zhang ${ }^{1}$, Tian \\ Lan $^{1}$, Kenneth Ka Ho Lee $^{3}$, Weidong Li ${ }^{1}$, Xiaoyu Song ${ }^{4}$, Jia Zhou ${ }^{5}$, Xuesong Yang ${ }^{2}$ \\ and Lijing Wang ${ }^{1}$ \\ ${ }^{1}$ Vascular Biology Research Institute, Guangdong Pharmaceutical University, Guangzhou, China \\ ${ }^{2}$ Key Laboratory for Regenerative Medicine of the Ministry of Education, Division of Histology \& Embryology, Medical College, \\ Jinan University, Guangzhou, China \\ ${ }^{3}$ Key Laboratory for Regenerative Medicine of the Ministry of Education, School of Biomedical Sciences, Chinese University \\ of Hong Kong, Shatin, Hong Kong, China \\ ${ }^{4}$ Key Laboratory of Medical Cell Biology, China Medical University, He Ping District, Shen Yang City, Liao Ning Province, China \\ ${ }^{5}$ Chemical Biology Program, Department of Pharmacology and Toxicology, University of Texas Medical Branch, Galveston, \\ TX, United States \\ * These authors contributed equally to this work \\ Correspondence to: Lijing Wang, email: wanglijing62@163.com
}

Xuesong Yang, email: yang_xuesong@126.com

Keywords: glipizide; anticancer; metastasis; tumor angiogenesis; natriuretic peptide receptor A

Received: July 18, $2014 \quad$ Accepted: September 15, $2014 \quad$ Published: September 16, 2014

This is an open-access article distributed under the terms of the Creative Commons Attribution License, which permits unrestricted use, distribution, and reproduction in any medium, provided the original author and source are credited.

\section{ABSTRACT}

Angiogenesis is involved in the development, progression and metastasis of various human cancers. Herein, we report the discovery of glipizide, a widely used drug for type 2 diabetes mellitus, as a promising anticancer agent through the inhibition of tumor angiogenesis. By high-throughput screening (HTS) of an FDA approved drug library utilizing our in vivo chick embryo chorioallantoic membrane (CAM) and yolk sac membrane (YSM) models, glipizide has been identified to significantly inhibit blood vessel formation and development. Moreover, glipizide was found to suppress tumor angiogenesis, tumor growth and metastasis using xenograft tumor and MMTV-PyMT transgenic mouse models. We further revealed that the anticancer capability of glipizide is not attributed to its antiproliferative effects, which are not significant against various human cancer cell lines. To investigate whether its anticancer efficacy is associated with the glucose level alteration induced by glipizide application, glimepiride, another medium to long-acting sulfonylurea antidiabetic drug in the same class, was employed for the comparison studies in the same fashion. Interestingly, glimepiride has demonstrated no significant impact on the tumor growth and metastasis, indicating that the anticancer effects of glipizide is not ascribed to its antidiabetic properties. Furthermore, glipizide suppresses endothelial cell migration and the formation of tubular structures, thereby inhibiting angiogenesis by up-regulating the expression of natriuretic peptide receptor $A$. These findings uncover a novel mechanism of glipizide as a potential cancer therapy, and also for the first time, provide direct evidence to support that treatment with glipizide may reduce the cancer risk for diabetic patients. 


\section{INTRODUCTION}

Angiogenesis is a cellular process that involves the sprouting of capillaries and configuration of the neovasculature from existing blood vessels $[1,2]$. Physiological angiogenesis occurs mainly during embryogenesis to accommodate the requirements of development and for this reason, only $0.01 \%$ the epithelial cells (ECs) undergo cell division in adults [1]. Nevertheless, angiogenesis plays a critical role in a variety of pathological conditions such as rheumatoid arthritis, diabetic retinopathy, inflammation, stroke and carcinogenesis [2,3]. Growth of the solid tumors requires a corresponding expansion of the vascular networks to maintain the increasing demand for blood supply. When this supply is insufficient, it leads to tumor cell necrosis and apoptosis or metastasis - depending on the aggressiveness of the neoplastic cells and their microenvironment [3]. Therefore, developing novel agents that are capable of inhibiting tumor angiogenesis represents a new paradigm in cancer prevention and treatment. Chick embryo chorioallantoic membrane (CAM) and yolk sac membrane (YSM) as in vivo models of angiogenesis were established and commonly utilized to facilitate the study of tumor angiogenesis and development of anti-angiogenic or pro-angiogenic agents $[4,5]$. We envisioned that high-throughput screening (HTS) of commonly used medicines with our in vivo CAM and YSM assays may lead to the discovery of novel anticancer therapeutics aimed at tumor angiogenesis.

Glipizide is a widely used drug in the treatment of type II diabetes since the 1950s because of its ability to stimulate insulin secretion from $\beta$-cells [6-8]. Recent studies have shown that diabetic patients have higher risks of developing colorectal, liver, pancreatic and prostate cancers [9-14]. Intriguingly, epidemic study has revealed that long-term use of some antidiabetic drugs such as gliclazide and glibenclamide alone or in combination with glipizide may result in a reduced risk of developing cancer in a dose-dependent manner from a cohort study of 6103 type-2 diabetic patients [15]. Nevertheless, it remains unclear how this class of antidiabetic drugs is associate with the decreased cancer risk in the diabetic patients with these treatments. The findings disclosed in our study provide the direct evidence to support such outcomes of glipizide in cancer prevention associated with the inhibition of angiogenesis.

Natriuretic peptides (NPs) belong to a family of polypeptide hormones that contains three isoforms: atrial natriuretic peptide (ANP), B-type natriuretic peptide (BNP), and C-type natriuretic peptide (CNP). These NPs are produced by the heart, vasculature and kidney. They play an important role in cardiovascular homeostasis, which is mediated by their receptors, natriuretic peptide receptors $A$ and $B$ (NPRA and NPRB) through the cytoplasmic guanylyl cyclase domains. NPRA is strongly expressed in the vasculature, kidneys and adrenal glands while NPRB is expressed in the brain. NPRA is also expressed in tumor cells (such as lung and prostate cancer cells) and inhibition of NPRA has been reported to inhibit tumor growth by suppressing cell proliferation [16-18]. Furthermore, activation of NPRA signaling could result in tumor growth by inducing stem cell recruitment and angiogenesis [19].

In this study, by screening of an FDA approved drug library utilizing our in vivo CAM and YSM models, glipizide has been identified to significantly inhibit blood vessel formation and tumor development. Here we report that glipizide inhibits tumor growth and metastasis in 4T1 transplanted tumor and spontaneous breast cancer in MMTV-PyMT transgenic mice. Further studies suggest that glipizide inhibits tumor-induced angiogenesis through up-regulation of NPRA, thereby suppressing tumor growth and metastasis.

\section{RESULTS}

\section{Glipizide inhibits angiogenesis in CAM and YSM models}

The high-throughput screening of an FDAapproved drug library of 480 compounds was carried out utilizing our CAM and YSM assays, aiming at the discovery of potentially new antiangiogenic molecules. In our initial effort using the CAM approach, 27 potential antiangiogenic drugs have been identified, and subjected to the investigation of effects inhibiting angiogenesis using the YSM assay. Consequently, one compound was narrowed down out of the 27 compounds (Supplemental Table S1), leading to the discovery of glipizide (Its chemical structure shown in Figure 1A) as the most effective drug in inhibiting angiogenesis.

We further validated the effect of glipizide on angiogenesis by simply administrating glipizide on the vascular plexus of CAM and YSM. Chick embryos were treated with 2, 4 and $8 \mu \mathrm{g}$ of glipizide or DMSO (control) for $48 \mathrm{~h}$ and then photographed (Figure 1B). We found that glipizide treatment led to a significant reduction in the density of CAM blood vessel plexus as compared with the control (Figure 1C). The YSM model was used to further confirm that glipizide could inhibit angiogenesis. Unshelled fertilized eggs were incubated inside sterile petri dishes for 9 days and then treated with glipizide $(2,4$ and $8 \mu \mathrm{g})$ or DMSO for $24 \mathrm{~h}$ within plastic rings (Figure 1D). The vascular beds on the egg yolk were photographed at 0,12 and $24 \mathrm{~h}$. The results revealed that extension of the blood vessel plexus was significantly inhibited by exposure to glipizide (Figure 1D). The blood vessel density was also significantly impaired by glipizide (Figures $1 \mathrm{E}$ and $1 \mathrm{~F}$ ). These data suggest that glipizide 
directly affects angiogenesis during the development of chick embryo.

\section{Glipizide suppresses 4T1 and B16F10 xenograft tumor growth and metastasis}

Given that glipizide is capable of inhibiting angiogenesis in the chick embryo, we speculated that glipizide may also suppress tumor-induced angiogenesis, thereby mitigating tumor growth and metastasis. To this end, we employed a mouse xenograft model with mouse breast cancer $4 \mathrm{~T} 1$ cells. Glipizide $(5 \mathrm{mg} / \mathrm{kg})$ and glimepiride $(4 \mathrm{mg} / \mathrm{kg}$ ) were administered daily for 14 days after subcutaneous inoculation of 4T1 cells into mouse mammary fat pad. Glipizide was found to significantly inhibit tumor growth (Figure 2A) and weight (Figure 2B).
In contrast, glimepiride has no significant effect on the tumor growth. Compared with the DMSO treatment, the postprandial blood glucose levels of the mice treated with the glipizide and glimepiride significantly decreased 30 min later and returned to normal $12 \mathrm{~h}$ later (Supplemental Table S2). Glipizide treatment also significantly reduced lung metastasis when 4T1 cells were intravenously administered as compared with the DMSO or glimepiride group (Figure 2C). Furthermore, glipizide was also found capable of inhibiting B16F10 melanoma growth and metastasis (Supplemental Figure S1). In addition, glipizide abolishes the CD31 staining for MVD (Figure 2D). However, there were not significant effects on tumor cell proliferation in glipizide-treated tumor as compared with the control (Figure 2E). These results collectively suggest that glipizide inhibits the tumor growth and metastasis of malignant melanoma and breast cancer by impeding

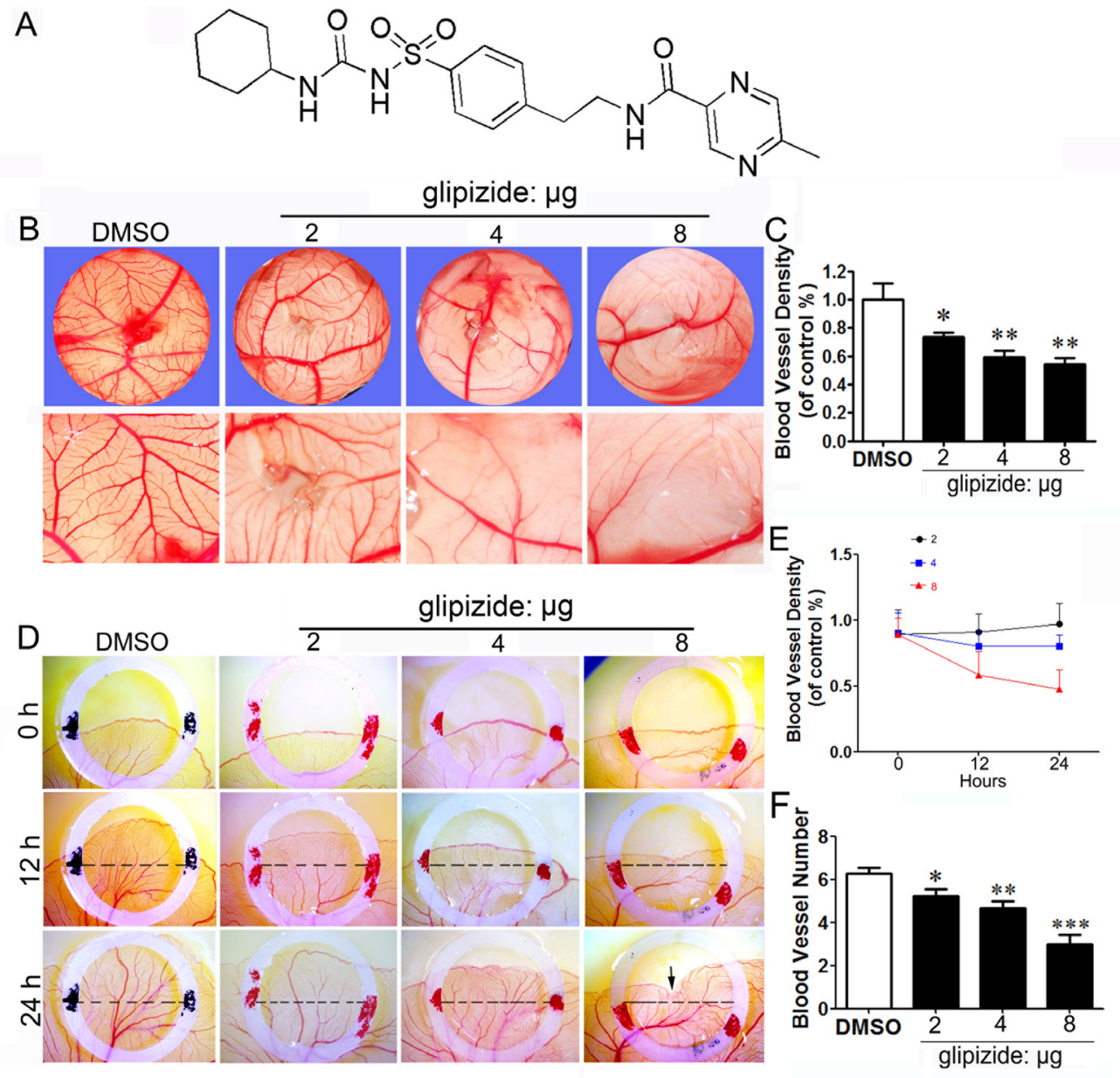

Figure 1: Glipizide inhibits angiogenesis in embryonic CAM and YSM assays. Chick CAM and YSM assays were used to determine whether glipizide can inhibit angiogenesis to suppress tumor growth. (A) Chemical structure of glipizide. (B) The upper panels show that the blood vessel plexus of 11-day-old chick embryos following treatment with 2, 4 and $8 \mu \mathrm{g}$ of glipizide or DMSO. The lower panels show the appearance of blood vessel plexus at higher magnification as indicated by white dotted squares in upper panels. (C) The bar chart shows the relative blood vessel density on CAM following glipizide and DMSO treatment. (D) The entire egg content was transferred into a sterile petri dish after two-day incubation. The upper panels show the appearance of the blood vessel plexus at the start of experiment $(0 \mathrm{~h})$ for control and 2, 4 and $8 \mu \mathrm{g}$ of glipizide. The middle and lower panels show the appearance of blood vessel plexus after $12 \mathrm{~h}$ and $24 \mathrm{~h}$ incubation, respectively. (E) Statistical chart shows the blood vessel density for control and glipizide treatment group. (F) Bar chart compares the number of blood vessels on YSM between control and glipizide treatment group. ${ }^{*} p<0.05 ; * * p<0.01$. 
tumor-induced angiogenesis.

\section{Glipizide impedes spontaneous tumor growth and metastasis in MMTV-PyMT transgenic mice}

The inhibitory effect of glipizide on tumor growth and metastasis was further investigated using the spontaneous murine model of breast cancer. MMTVPyMT transgenic mice spontaneously develop widespread multifocal adenocarcinomas in the entire mammary epithelium which develop into palpable mammary tumors in 5 weeks and older mice. These tumors metastasize to the lung with $80-94 \%$ incidence [20]. To study the effect of glipizide on the spontaneous mammary tumors, we randomly selected eight MMTV-PyMT mice as the control and another eight for glipizide treatment $(5 \mathrm{mg} / \mathrm{kg})$. The tumor volumes were measured and calculated every 4 days. Comparison of the control and glipizide treatment group revealed that the tumor volume in glipizide-treated mice was significantly reduced (Figure 3A). Meanwhile, the blood glucose levels were significantly decreased at 30 min after the glipizide treatment (Supplemental Table S3). The mice were sacrificed and tumors harvested 20 days after the glipizide treatment. There was significant difference in the tumor weight between control and glipizide-treated mice (Figure 3B). Intriguingly, it was found that there were fewer metastasis sites on the lung surface of glipizide treatment mice (Figure 3C). Immunohistological staining for CD31 was performed on the tumor sections. The results demonstrated a reduction in microvessel density in glipizide-treated tumor as compared with the control (Figure 3D). However, glipizide had no significant effect on the BrdU staining for tumor cell proliferation (Figure 3E).

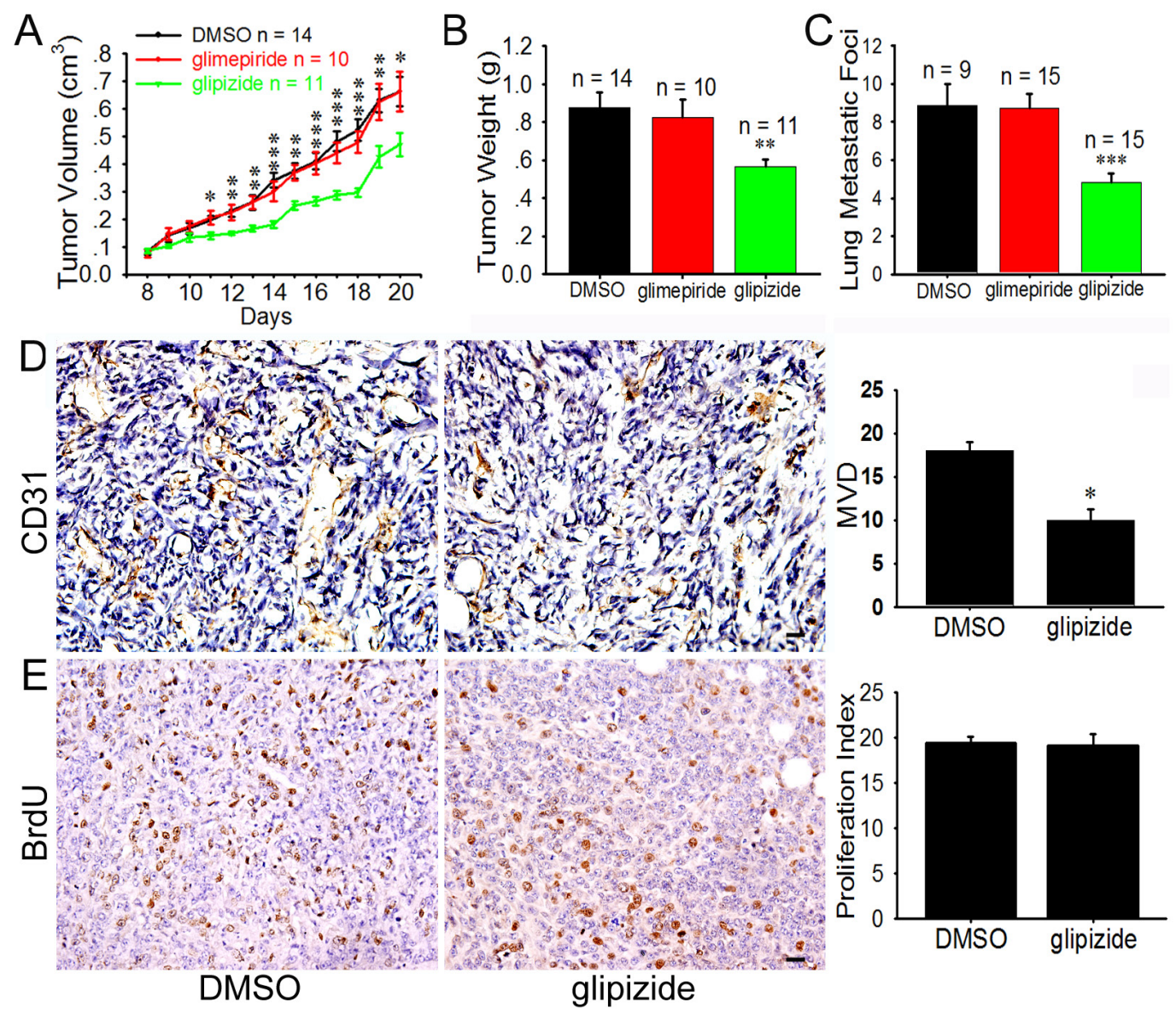

Figure 2: Glipizide inhibits angiogenesis, tumor growth and metastasis of breast cancer 4T1 cells. 4T1 cells were injected into mammary mouse pad and when tumors were palpable on day 7 , they were injected with glipizide $(5 \mathrm{mg} / \mathrm{kg}), \mathrm{glimepiride}(4 \mathrm{mg} / \mathrm{kg})$ or DMSO (control) once every day. (A) The volume of the breast tumors was measured every day and revealed that the tumor volume significantly decreased after glipizide treatment. (B) Tumors were weighed on 20 days after inoculation. There was significant difference between the weights of glipizide and glimepiride or DMSO treated tumors. (C) Incidence of lung metastasis enumerating from the breast tumors after glipizide, glimepiride and DMSO treatments. (D) Immunohistological staining against CD31 was performed on tumor tissues sections. The staining shows the microvascular density was decreased in the glipizide treatment group. (E) Glipizide displayed no significant effect on tumor cell proliferation. Abbreviation: MVD, microvascular density. Results are given as mean \pm S.D. Values of three independent experiments (A-C) or at least five randomly selected sections per animal (D). Scale bars $=20 \mu \mathrm{m}$ in $\mathrm{D}$ and $\mathrm{E}$. * $p<0.05 ; * *$ $p<0.01 ; * * * p<0.001$. 


\section{Glipizide inhibits MCF-7 cell growth and angiogenesis on CAM}

Correlation between tumor growth and angiogenesis was further investigated by introducing MCF-7 cells to the surface of 10-day old embryo CAM. The CAM model allows glipizide $(2,4$ and $8 \mu \mathrm{g})$ to directly exert its effect on tumor angiogenesis (Figures 4A, 4B and $4 \mathrm{E})$. We found tumor volume and microvascular density were significantly reduced following glipizide treatment in a dose-dependent manner as compared with control (Figures $4 \mathrm{E}$ and $4 \mathrm{~F}$ ). H\&E staining revealed that in the control (DMSO) group there was no necrosis amongst the blood vessels. However, necrosis increased with decrease in blood vessel density following glipizide treatment (Figure 4C). Furthermore, we investigated the expression of VEGFR-2, which is specific in capillary endothelial cells. It was found that the expression of VEGFR-2 was gradually down-regulated in blood vessels with increasing the concentration of glipizide (Figure 4D). These results indicate that glipizide reduces breast cancer growth by inhibiting tumor-induced angiogenesis in vivo.

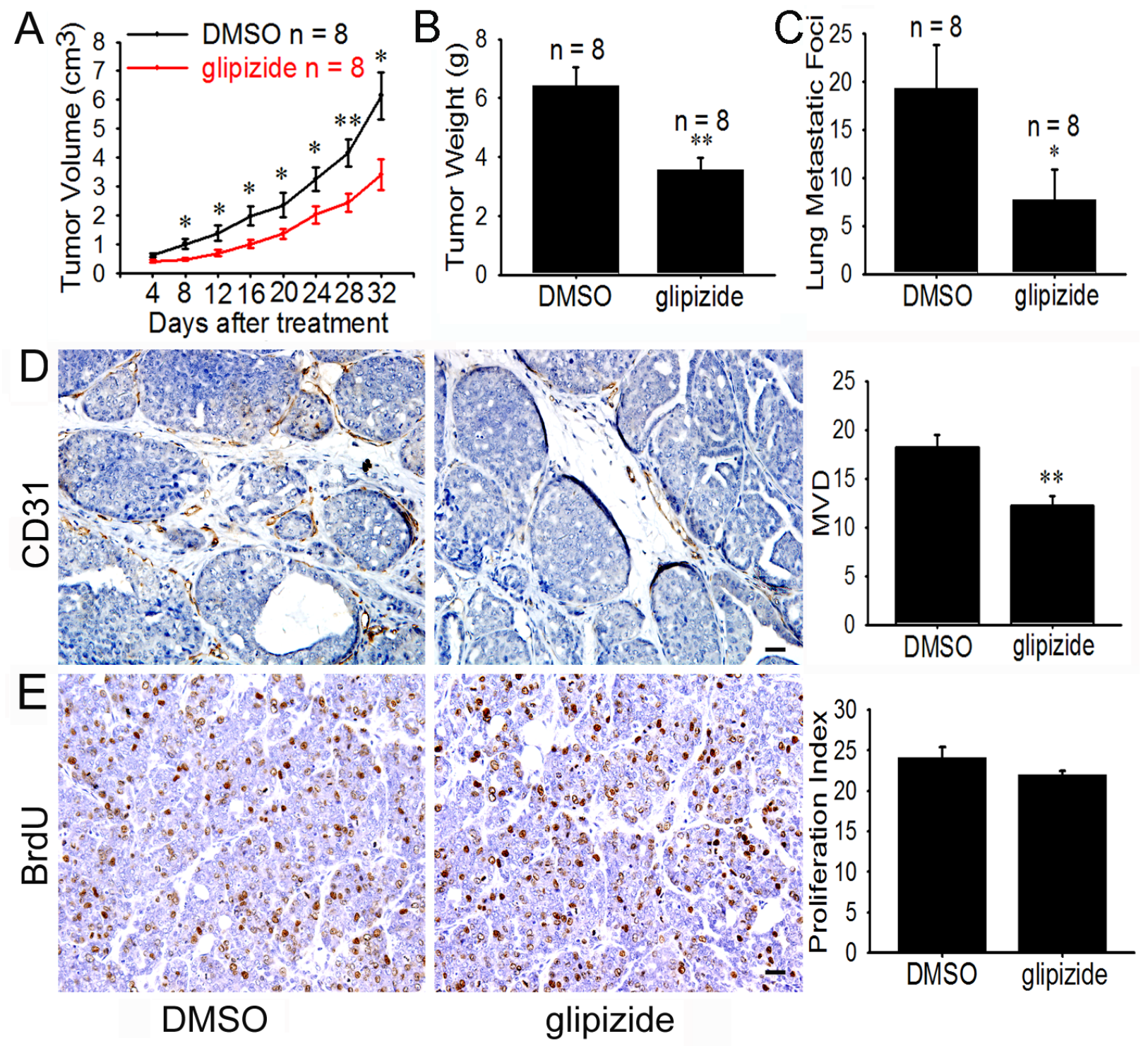

Figure 3: Glipizide suppresses angiogenesis, tumor growth and metastasis of spontaneous breast cancer. (A) 9-weekold female MMTV-PyMT mice were allowed to spontaneously develop breast cancer and then given DMSO or glipizide $(5 \mathrm{mg} / \mathrm{kg})$ intraperitoneally, once every three days. The results show glipizide inhibits tumor growth. (B and C) After the mice were sacrificed, both the lungs and the breast tumor were harvested. The presence of metastatic foci on the lung surface was counted and the breast tumors weighed. The results show glipizide reduces the number of lung metastatic foci but has no effect on the weight of the tumors. (D and E) Immunohistological staining on tumor tissues sections revealed that glipizide inhibited tumor-induced angiogenesis, but not tumor cell proliferation. Abbreviation: MVD, microvascular density. Scale bars $=20 \mu \mathrm{m}$ in D and E. ${ }^{*} p<0.05 ; * * p<0.01$. 


\section{Glipizide does not affect 293T, 4T1 and MCF- 7 cell proliferation, but inhibits the HUVEC migration and tube formation}

Now that glipizide inhibits breast cancer growth and metastasis in vivo, it is interesting to explore whether glipizide directly inhibits tumor cell proliferation. Hence, we evaluated the effects of glipizide on human kidney epithelial 293T, 4T1 and MCF-7 cell proliferation. These cells were treated with $1-256 \mu \mathrm{M}$ of glipizide for 48 or $72 \mathrm{~h}$. Cell viability was detected using MTT assay. It was determined that glipizide exposure on any of these 3 cell types has no significant impact on cell proliferation at all

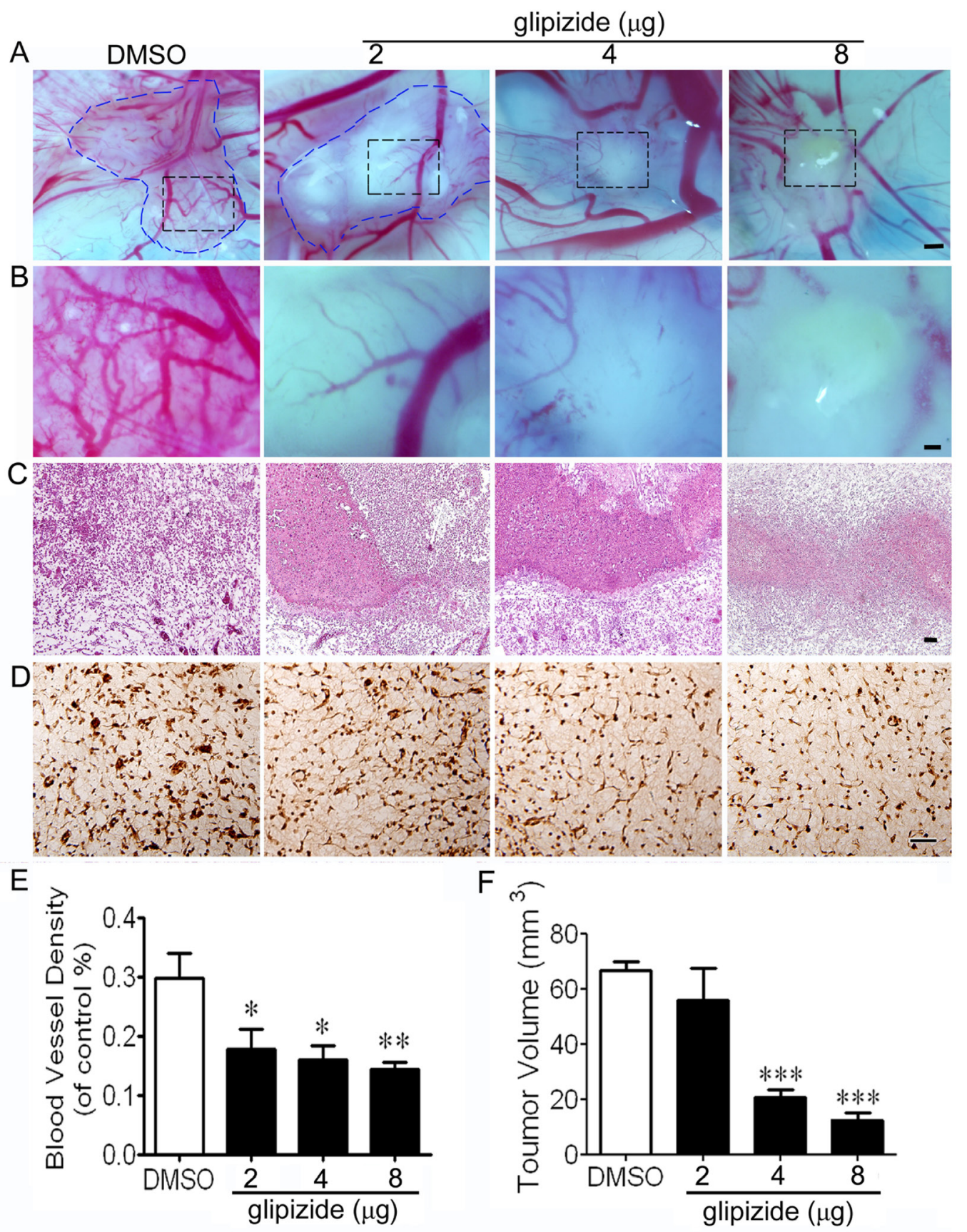

Figure 4: Glipizide suppresses breast cancer growth and angiogenesis. MCF-7 breast cancer cells were xenografted onto the surface of 8-day chicken CAM. (A) Representative images of the cancer xenografts treated with DMSO or 2, 4 and $8 \mu \mathrm{g}$ of glipizide. (B) Higher magnification of the black dotted squares in A. (C) Xenografts stained with H\&E. (D) ISH staining against VEGFR-2 was performed and the staining shows the expression of VEGFR-2 during experimental breast cancer development. (E and F) Bar chart shows the differences in blood vessel density and tumor volume measurement of glipizide and DMSO treated xenografts on CAM. $* p<0.05 ; * *$ $p<0.01$. Scale bars $=500 \mu \mathrm{m}$ in $\mathrm{A} ; 200 \mu \mathrm{m}$ in $\mathrm{B}$ and $50 \mu \mathrm{m}$ in $\mathrm{C}$. 
tested dosages (Figures 5A-C).

In view of the effect of glipizide on tumor cell proliferation and angiogenesis in CAM and YSM, we further determined the effect of glipizide on human umbilical vein endothelial cells (HUVEC) tube formation in vitro. We found that glipizide, even at the highest concentration $(256 \mu \mathrm{M})$ tested, did not appreciably interfere with HUVEC growth in culture (Figure 5D). Cell migration, mediated by chemoattractants produced by vascular endothelial cells, is a hallmark of angiogenesis. In the CAM \& YSM experiments, we observed that glipizide impaired angiogenesis. Hence, we examined HUVEC migration inside Boyden Chambers. We found that glipizide significantly attenuated HUVEC migration in a dose-dependent manner (Figure 5E). We also performed tube formation assay to determine the actions of glipizide on capillary formation flowing the introduction of HUVECs to monolayered Matrigel. As expected, glipizide-, but not DMSO-, treated HUVECs were inhibited from developing spider-like microvascular capillaries in a dose-dependent manner (Figures $5 \mathrm{~F}$ and $5 \mathrm{G})$.

\section{Glipizide inhibits angiogenesis through induction of vascular NPRA expression}

We performed qRT-PCR array analysis for angiogenesis associated genes, using RNAs isolated from DMSO- and glipizide-treated HUVECs. We found that glipizide significantly induced NPRA expression amongst 90 known angiogenic related genes (Figure 6A). Interestingly, glipizide induces NPRA, but not NPRB
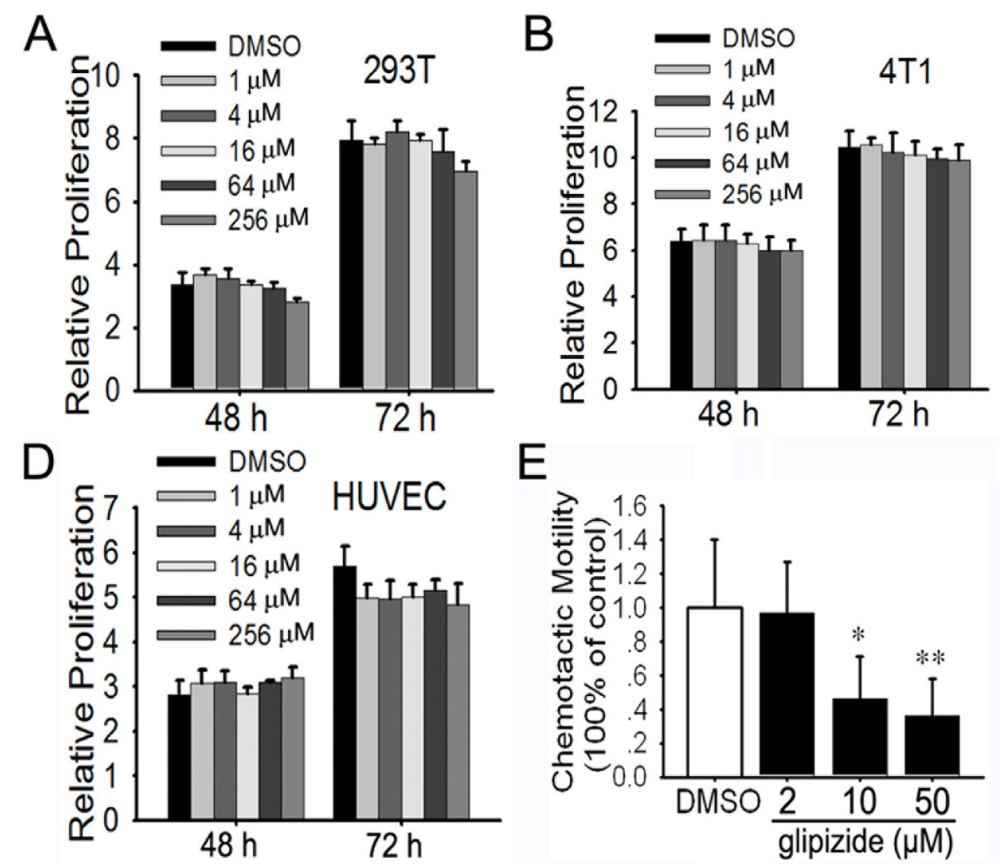

$\mathrm{E}$
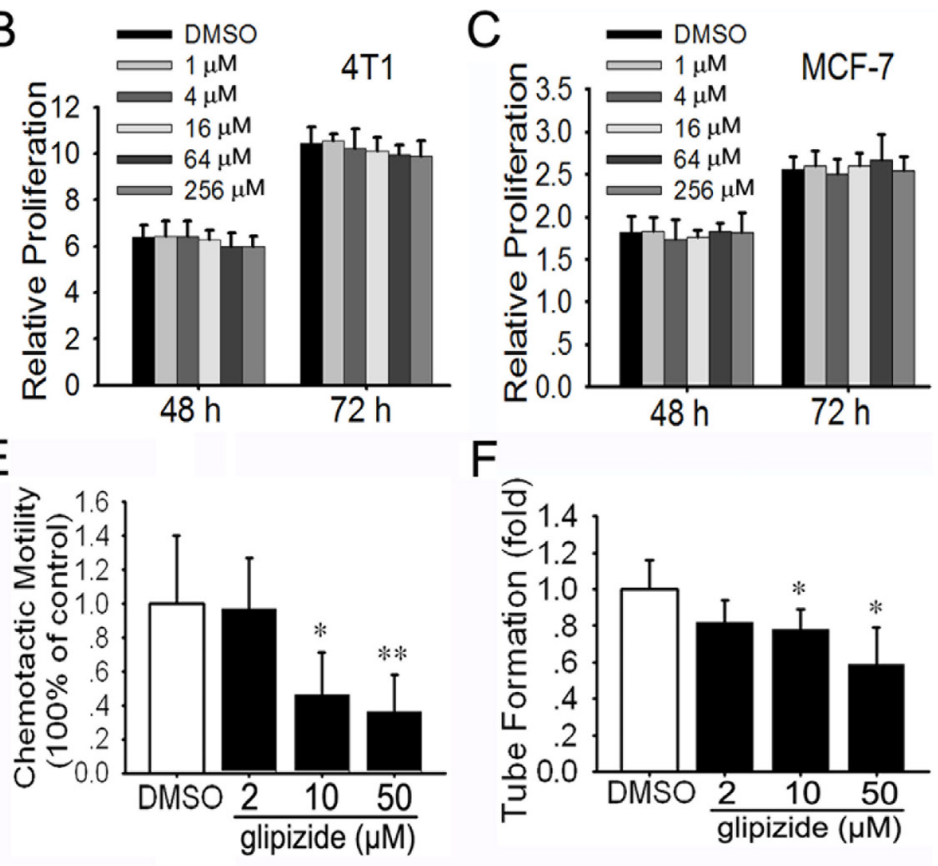

$\mathrm{F}$

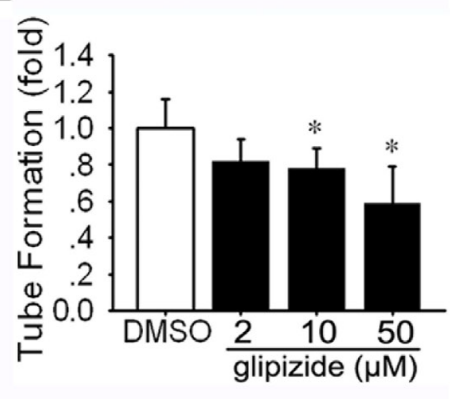

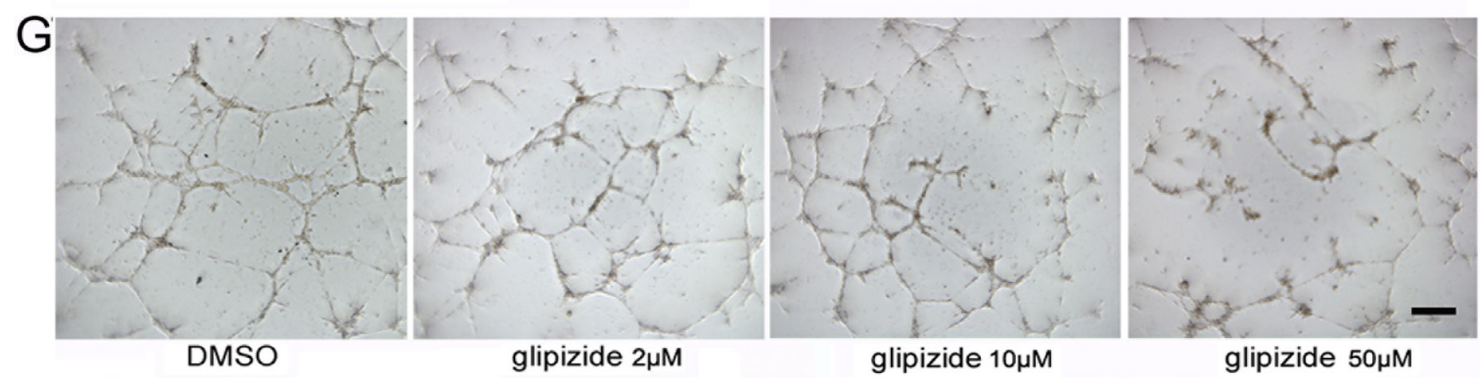

Figure 5: Glipizide shows no effects against cell proliferation, but inhibits endothelial cell migration and tube formation. (A-C) MTT assay was performed on 293T (human kidney epithelium) (A), 4T1 (mouse breast cancer) (B), and MCF-7 (human breast cancer) cells (C) after treatment with $1-256 \mu \mathrm{M}$ of glipizide for $48 \mathrm{~h}$ or $72 \mathrm{~h}$. The results show no effect on cell proliferation and viability. (D) HUVEC cells were treated with $1-256 \mu \mathrm{M}$ of glipizide for 48 or $72 \mathrm{~h}$ to establish the effect of glipizide on HUVEC proliferation. MTT assay shows $1-256 \mu \mathrm{M}$ of glipizide does not suppress HUVEC proliferation. (E) The migration ability of HUVEC was evaluated using boyden chambers. HUVECs suspended various concentrations of glipizide were introduced into the upper chamber and allowed to migrate through the interposing filter for $12 \mathrm{~h}$. The results show HUVECs migration was significantly reduced in the presence of 10 and $50 \mu \mathrm{M}$ of glipizide. (F and G) HUVECs were cultured on matrigel in the presence of glipizide or DMSO for $5 \mathrm{~h}$ and the formation tubes were recorded (G). The length of the tubes was measured and difference between glipizide and DMSO treatment was statistically analyzed (F). Data are presented for at least three independent experiments. ${ }^{*} p<0.05,{ }^{* *} p<0.01$. Scale bars $=50 \mu \mathrm{m}$ in G. 
and C, expression (Figure 6B). To confirm this finding, cultured HUVECs were immunofluorescently stained with NPRA and CD31 antibodies. Western blotting confirmed NPRA expression was increased in HUVEC treated with glipizide and the intensity of staining increased in a dosedependent manner (Figure 6C). The immunofluorescent staining (Figure 6D and Supplemental Figure S2) also confirmed such observations. We examined whether glipizide could also up-regulate NPRA expression in the tumor endothelial cells of MMTV-PyMT mice. As expected, treatment of MMTV-PyMT mice with glipizide but not with DMSO, induced NPRA expression in CD31 ${ }^{+}$ endothelial cells within solid breast tumors (Figure 6E).
The NPRA staining was unevenly distributed along the tumor-induced vasculature, attesting to the ability of glipizide to act in vivo.

We assessed the importance of NPRA in angiogenesis by examining whether silencing NPRA can promote tube formation by HUVECs while ectopic expression of NPRA produces an inverse effect. We acquired plasmids carrying NPRA short-hairpin RNAs (shRNAs) and full-length NPRA cDNA. It has demonstrated that after silencing NPRA expression, the HUVECs increased microvascular tube formation while over-expression of NPRA inhibited tube formation (Figure 6F and Supplemental Figure S3). Furthermore, glipizide
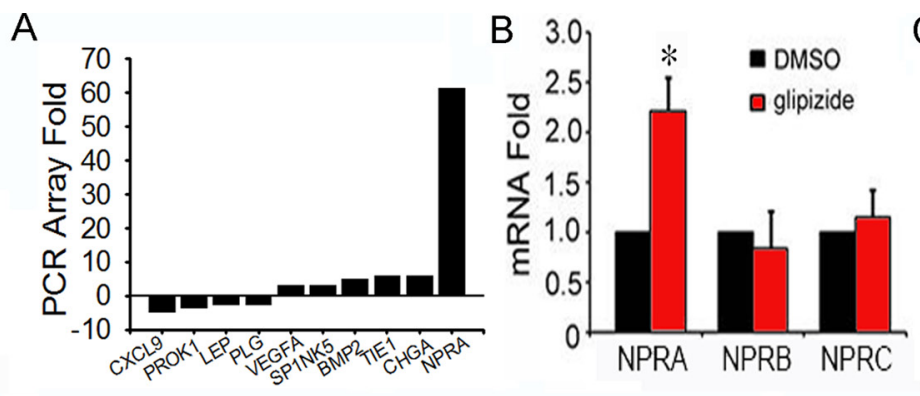

C
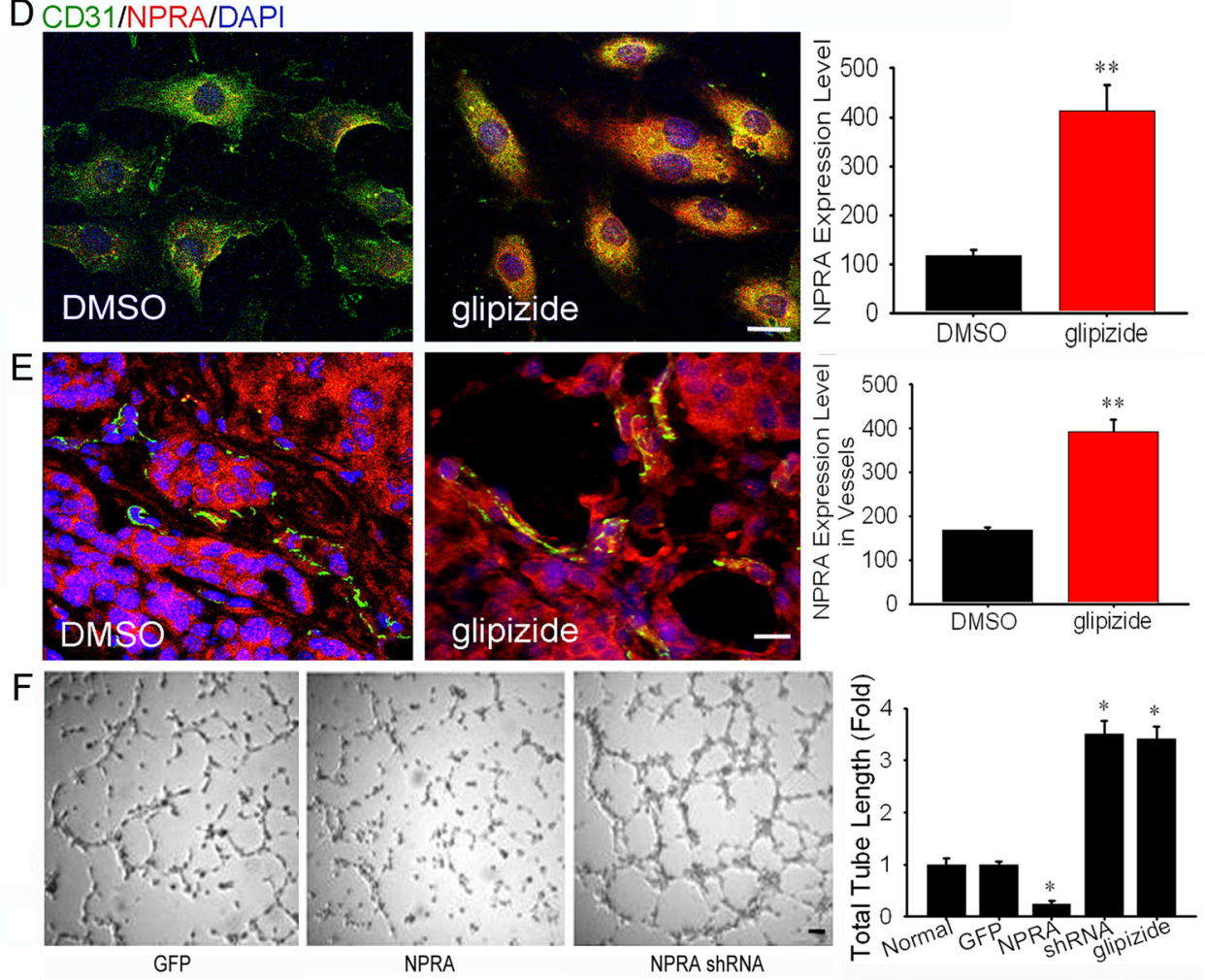

Figure 6: Glipizide inhibits angiogenesis through induction of NPRA expression. (A) qRT-PCR array of genes associated with angiogenesis revealed NPRA expression was up-regulated 61-fold in HUVEC cells following glipizide treatment. (B-D) qRT-PCR (B), western blotting (C) immunofluorescent staining (D) were performed to confirm the microarray results. (E) Immunofluorescent staining revealed CD31 (endothelial cell marker) and NPRA was strongly expressed in the blood vessels of the spontaneous formed tumor tissues of MMTV-PyMT mice. (F) HUVEC cells transfected with GFP plasmid, full length human NPRA cDNA or NPRA shRNA. The effects of NPRA overexpression and silencing on vascular tube formation were examined $24 \mathrm{~h}$ after electroporation. The full length NPRA cDNA or NPRA shRNA induced NPRA over-expression or silencing in HUVEC cells shows silencing NPRA significantly increased the ability of HUVEC cells to form tubular structures. Furthermore, the ability of NPRA silencing HUVEC cells to form tubular structures did not change after glipizide treatment. $* p<0.05, * * p<0.01$. Scale bars $=20 \mu \mathrm{m}$ in D and $\mathrm{E}$ and $100 \mu \mathrm{m}$ in $\mathrm{F}$. 
did not influence HUVECs tube formation after NPRA was silenced (Figure 6F). These results are consistent with previous finding that NPRA activation increases endothelial permeability $[21,22]$, demonstrating the functional significance of NPRA in modulating vascular homeostasis.

\section{DISCUSSION}

In this study, we report a significant finding that glipizide, a widely used antidiabetic drug, can potently inhibit angiogenesis by up-regulating NPRA expression in the vascular endothelial cells. Consequently, this leads to a reduction in microvessel density which attenuates tumor growth and metastasis - as determined using xenograft mouse models with breast carcinoma 4T1 cells and spontaneous breast carcinoma MMTV-PyMT mice.

The embryonic CAM and YSM assays are well established methods used in biological and pharmaceutical research because they are relatively simple and inexpensive, but highly reproducible [23]. In our preliminary studies, we used CAM and YSM approaches to screen an FDA approved drug library consisting of 480 compounds. Utilizing this high-throughput screen, glipizide has been identified with potent inhibitory effects on blood vessel formation within CAM and YSM. As such, we speculated that glipizide might be able to suppress tumor growth and metastasis by inhibiting tumorinduced angiogenesis.

On the other hand, recent pharmacoepidemiological surveys show that the use of antidiabetic drugs may influence cancer risk in type 2 diabetes mellitus. It has been reported that metformin, a widely used antidiabetic drug, is related to a reduced cancer incidence by acting on the aging process [24] and can potentiate chemotherapy in combination with rapamycin [25]. Furthermore, metformin can prevent breast cancer, especially chemoresistant or trastuzumab-resistant breast cancer, by targeted killing of cancer stem cell (CSC)-like breast cancer cells [26, 27]. It was reported that the patient treatment with glipizide or the same class of analogues may be associated with a lower cancer mortality than that with metformin [28]. Monami et al. [29] found that glibenclamide users had greater cancer-related mortality than gliclazide users. They reported that gliclazide treatment reduced cancer risk compared with that of glibenclamide [30]. It was also found that the diabetic patients treated with glipizide and metformin have lower risk to get cancer [31]. However, the relevant mechanism for such outcomes was unraveled. Our findings that glipizide attenuates angiogenesis, tumor growth and metastasis of inoculated mouse breast cancer 4T1 cells and MMTV-PyMT-driven breast carcinogenesis have provided direct evidence to support the cancer preventive and therapeutic effects of glipizide. Furthermore, we revealed the hypoglycemia developed in the mice treated with glipizide and glimepiride. However, there was no significant difference of the volume and weight between glimepiride and DMSO treatment, indicating the inhibition of tumor growth induced by glipizide treatment was not attributed to hypoglycemia. In addition, it was reported that the human plasma concentrations of glipizide are typically in the range of $50-300 \mathrm{ng} / \mathrm{mL}$ in diabetic patients receiving the drug therapeutically [32]. The glipizide dose of $100 \mu \mathrm{g}$ per $20 \mathrm{~g}$, which was administered to treat the tumor mice in our experiments, is consistent with the clinically used dose according to the body surface area. Therefore, the plasma concentrations of glipizide in tumor mice receiving the drug therapeutically are similar to those previously reported in patients, suggesting that glipizide may have an excellent safety profile as a potential anticancer drug for clinic use [33]. Given that bringing a new drug from discovery to the market is highly time-consuming and a costly process, repurposing of existing drugs represents an attractive strategy of cancer drug development [34]. To this end, our findings have demonstrated the promise of glipizide as a novel therapeutic that may benefit the cancer patients.

The tumor xenograft and transgenic mice experiments implied that angiogenesis might be involved in the inhibition of tumor growth and metastasis. We found that glipizide inhibited angiogenesis, tumor growth and metastasis in various tumor models. In order to discriminate the effects of glipizide on tumor cell proliferation and angiogenesis, we maintained breast cancer xenografts on chick CAM. The procedure allowed us to directly examine the correlation between tumor tissue and tumor angiogenesis in the presence of glipizide. Chick CAM assay has been extensively used in the past for this purpose [35]. We noticed that glipizide reduces the volume of the growing tumor in a dose-dependent manner. Likewise, the density of the vascular plexus in the tumor density also dramatically decreased. Our MTT assay revealed that glipizide has no significant effect against tumor cell proliferation. We also discovered that glipizide inhibited cell migration and the ability of these vascular endothelial cells to form tubular structures. These findings support glipizide inhibits tumor angiogenesis which results in tumor regression but not through suppressing tumor cell proliferation. Since angiogenesis is essential for tumor growth and metastasis, it has been widely trumpeted as a target for limiting tumor growth. Judah Folkman in 1971 was the first to suggest that tumor growth and metastasis were dependent on angiogenesis, and speculated that blocking angiogenesis could be an effective approach for inhibiting tumor growth and metastasis [36]. Given that antiangiogenic therapy presents advantages over other anticancer strategy, glipizide as a novel antiangiogenic inhibitor may be developed as a promising anticancer agent for clinical use.

To acquire a molecular insight into how glipizide suppresses angiogenesis, and better understand the 
relevant signaling pathways that glipizide exerts on the vascular endothelial cells, we performed qRT-PCR array analysis on glipizide-treated HUVECs for genes known to be associated with angiogenesis. We identified NPRA as the potential target and established that glipizide inhibited angiogenesis through the induction of NPRA expression in vascular endothelial cells. Sabrane et al. [22] reported that NPRA activation increases endothelial cell permeability, demonstrating that the receptor plays an important role in modulating vascular homeostasis. Meanwhile, it was recently reported that in NPRA-KO mice there was significantly lower angiogenic response compared with their wild-type counterparts [19]. NPRA has been shown to be expressed in cancer cells and proposed to be a potential prognostic marker and a target for cancer therapy [17,18]. Although Mallela et al. [19] concluded that NPRA signaling was involved in tumor growth through regulating angiogenesis, they only demonstrated that the numbers of $\mathrm{CD} 31^{+}$cells were decreased in the lung cancer sections of NPRA-KO mice compared with the wild-type mice by IHC staining. While these studies reported NPRA promoted cancer development, the relationship between NPRA and angiogenesis in the other kinds of tumors was not examined [19]. Here, our in vitro experiment showed that glipizide could not affect HUVEC tube formation when NPRA was silenced. For the first time, we demonstrated the role of glipizide and NPRA in tumorinduce angiogenesis.

Taken together, this study has shown that glipizide is capable of inhibiting tumor growth and metastasis in the tumor xenograft and transgenic mouse models. The inhibitory effect was principally achieved through the suppression of tumor-induced angiogenesis instead of cancer cell proliferation. Furthermore, NPRA has been identified as one of the potential antiangiogenic molecular targets for glipizide. While more research efforts are needed to elucidate the exact molecular mechanisms associated with its suppressive action on tumor growth, glipizide has demonstrated the great potential to be developed as a novel and promising anticancer drug for the treatment of various human cancers.

\section{MATERIALS AND METHODS}

\section{Ethics Statement}

All animal experiments were conducted according to relevant national and international guidelines. And this project was approved by the Medical Research Animal Ethics Committee of Guangdong Pharmaceutical University. When tumor volume exceeded $2 \mathrm{~cm}^{3}$, mice were euthanized by cervical dislocation.

\section{Chemical reagents and cell lines}

A chemical library containing 480 FDA-approved drugs or drug candidates were purchased from BIOMOL Company (BML-2840-0100). All the compounds were marked with a drug code (A0-A19; B0-B19; ... X0-X19) and dissolved in dimethyl sulfoxide (DMSO, Amresco Company) to prepare $5 \mathrm{mg} / \mathrm{mL}$ stock solutions. Glipizide (cat. no. G117, Sigma, St Louis, MO, USA) was dissolved in DMSO to produce $5 \mathrm{mg} / \mathrm{mL}, 10 \mathrm{mg} / \mathrm{mL}$ and $20 \mathrm{mg} /$ $\mathrm{mL}$ stock solutions for validation studies. Mouse breast cancer 4T1 cell line, human breast cancer MCF-7 cell line, human renal epithelial $293 \mathrm{~T}$ cell line and human umbilical vein endothelial cell line were all purchased from the Institute of Biological Cells (Chinese academy of sciences, Shanghai, China).

\section{Chick embryos and mice}

Fertilized white leghorn chicken eggs were obtained from the Avian Farm of South China Agriculture University (Guangzhou, China). The egg shells were cleaned using a $1 \%$ solution of geramine and then incubated in an egg incubator at $37.5{ }^{\circ} \mathrm{C}$ and $50-60 \%$ humidity. Female 6 - 8 week old BALB/c mice were purchased from the animal center of Guangdong Province Medical School. MMTV-PyMT transgenic mice were obtained from the Jackson Memorial Laboratory. All the mice were weaned and tail-clipped at 4 weeks for genotyping by PCR. The primer pair used was specific for the MMTV-PyMT. All the mice were maintained in accordance with the NIH guidelines.

\section{Chick embryo chorioallantoic membrane (CAM) assay}

The CAM assay was performed as previously described with a slight modification [37]. Briefly, fertilized eggs were incubated for 9 days and then the shell above the air chamber was cut using a dental saw to create a small window $\left(10 \times 10 \mathrm{~mm}^{2}\right)$. After removal of the shell membrane with sterile forceps, 2,4 and $8 \mu \mathrm{g}$ of glipizide $(20 \mu \mathrm{L})$ were applied directly to the air chamber of 9-day chick embryos. In the control group, the same concentration of DMSO in $20 \mu \mathrm{L}$ of phosphate-buffered saline was applied. The eggs were then sealed with sterile medical tape and incubated at $37.8{ }^{\circ} \mathrm{C}$ and $60 \%$ humidity. After $48 \mathrm{~h}$ incubation, the CAM vasculature was photographed using a Canon camera. The images were analyzed using an image analysis program IPP 6.0 (Image Pro-Plus, version 6.0, Media Cybernetics) and the blood vessel density (percentage of blood vessel area over the whole area under microscopic field) was calculated. Each experiment was repeated twice with 10 eggs per 
experimental condition.

\section{Chick embryo yolk sac membrane (YSM) assay}

Eggs were incubated for 3 days and then the chicken embryos were transferred into sterilized culture dishes. The individual yolk-sac vessels were oriented facing upward. Two silastic rings (inside diameter: $9.5 \mathrm{~mm}$; outside diameter: $12 \mathrm{~mm}$ ) labeled with red and black marker pens, respectively, were placed in symmetrical position over the yolk sac vessel area of the chicken embryos. The culture dishes were then covered tightly before returning to the incubator. $40 \mu \mathrm{L}$ of glipizide $(50,100$ and 200 $\mu \mathrm{g} / \mathrm{mL}$ in gelatin) and DMSO were introduced into the rings of healthy embryos with well-developed vessels. Photographs of the vessels within the rings were captured at $0 \mathrm{~h}, 2 \mathrm{~h}$ and $24 \mathrm{~h}$ using an Image acquisition OPTPRO 2007 system. The images were quantitatively analyzed using an Image-Pro Plus 6.0 system, as described for the CAM assay.

\section{High-throughput screening for potential antiangiogenic drugs}

A $20 \mu \mathrm{L}$ aliquot of DMSO (control) or $50 \mu \mathrm{g} / \mathrm{mL}$ of one of 480 drugs (FDA-approved drug library) was added to each of the embryonic CAM or YSM membrane in the egg shell openings. The effect of all the tested compounds on angiogenesis was evaluated using the CAM and YSM assays.

\section{MCF-7 breast cancer assay on CAM}

To evaluate the direct effect of glipizide on angiogenesis, MCF-7 breast cancer cells were cultured and maintained on the CAM of 10 day-old chick embryos [38]. Briefly, a $1 \mathrm{~cm}$-diameter window was created in the shell of each 10 day-old fertilized egg. The CAM was exposed and a silastic ring was placed on top of the CAM. Then $40 \mu \mathrm{L}$ of $0-200 \mu \mathrm{g} / \mathrm{mL}(2,4$ and $8 \mu \mathrm{g})$ glipizide was added to the center of the ring on day 12 . On day 14 , the eggs were cut carefully along the axis of the median line and the content was discarded. The gross morphology of each CAM was recorded using a stereomicroscope (SZX16 Olympus). The antiangiogenic effect of glipizide was evaluated by comparing the number of secondand third-order blood vessels with CAM treated with DMSO (control). The size (volume) of the breast tumors present on the CAM was calculated (length $\times$ width $^{2} \times$ 0.52 ). Statistical analysis of second- and third-order vessels was performed using 2-tailed Student's t-test.

\section{T1 xenograft tumor model}

4T1 mouse breast cancer cell line was injected subcutaneously into the second right mammary fat pad area of 6-8-week-old BALB/c mice. After inoculation, the mice were then randomly divided into glipizide, glimepiride (cat. no. G2295, Sigma) or DMSO (control) treatment. DMSO, glimepiride $(4 \mathrm{mg} / \mathrm{kg}$ ) or glipizide $(5$ $\mathrm{mg} / \mathrm{kg}$, according to clinically used dosage) was injected intraperitoneally into the $4 \mathrm{~T} 1$ xenograft mice every day since the 4T1 cells were inoculated for six days. And the blood glucose levels were detected by blood glucose meter. The tumor volume was measured using a vernier caliper every three days and calculated using the formula: Volume $=$ length $\times$ width $^{2} \times 0.52$. The mice were treated with glipizide, glimepiride or DMSO for up to 20 days. The mice were then sacrificed and the tumors harvested for weighing and histological analysis.

\section{Metastasis assays}

$1 \times 10^{5} 4 \mathrm{~T} 1$ cells were injected into the tail vein of $\mathrm{BALB} / \mathrm{c}$ mice followed by treatment with $\mathrm{DMSO}$, glimepiride $(4 \mathrm{mg} / \mathrm{kg})$ or glipizide $(5 \mathrm{mg} / \mathrm{kg})$ on the same day of inoculation for 3 weeks. After 3 weeks, the mice were sacrificed, and their brains, lungs, livers, and kidneys were collected for analysis. The tissue samples were analyzed for the presence of metastatic foci and histology.

\section{MMTV-PyMT transgenic mice}

Nine-week-old MMTV-PyMT mice were intraperitoneally injected with DMSO or glipizide $(5 \mathrm{mg}$ / $\mathrm{kg}$ ) for 20 days. These mice spontaneous develop breast carcinoma. The tumors were measured every three days and the tumor volume was calculated: length $\times$ width $^{2} \times$ 0.52 . After 20 days, the mice were sacrificed and their tumors and lungs were collected for weighing, histological analysis and pulmonary metastatic foci counting.

\section{Immunohistological and immunofluorescent staining}

Immunohistochemistry and immunofluorescent staining were performed on $3-\mu \mathrm{m}$ and $6-\mu \mathrm{m}$ sections, respectively. Before immunohistochemical staining, transgenic and 4T1 xenograft mice were intraperitoneally injected with $100 \mathrm{mg} / \mathrm{kg}$ of 5-bromo-2'-deoxyuridine (BrdU; cat. no. B5002, Sigma). Briefly, the sections were dewaxed, hydrated and incubated anti-CD31 (1:100 dilution, cat. no. sc-1506, Santa Cruz, CA, USA), antiBrdU (1:100 dilution, cat. no. sc-32323, Santa Cruz, CA, USA) and anti-NPRA (1:100 dilution, cat. no. sc-25485, Santa Cruz) primary antibodies, overnight 
at $4{ }^{\circ} \mathrm{C}$. The binding of the primary antibodies to cells/ tissues was detected using the appropriate fluorescently labeled secondary antibody or HRP-conjugated secondary antibody plus DAB. All sections were the counterstained with hematoxylin or DAPI. The density of microvessels was quantified by counting the number of $\mathrm{CD} 31^{+}$vessels in a $200 \times$ field [39]. For BrdU quantitation, fields were randomly selected in a $400 \times$ field and the number of $\mathrm{BrdU}^{+}$cells were counted as a percentage of the total cells per field. The NPRA expression levels were quantified using an image analysis program IPP 6.0 (Image ProPlus, version 6.0, Media Cybernetics) in a $400 \times$ field and evaluated by two experimenters.

\section{In situ hybridization}

In situ hybridization (ISH) was performed to determine a vascular endothelial growth factor receptor-2 (VEGFR-2) [38]. The PCR product (365 bp) was cloned into T-vector with T3 and T7 promoter and the riboprobe was labeled with dNTP containing Bio-dUTP through transcribing T3 promoter transcriptase. After the tumor tissue sections were treated by proteinase $\mathrm{K}(0.2 \mathrm{mg} /$ $\mathrm{mL}$ ), the probe was incubated overnight at $37^{\circ} \mathrm{C}$. Then the Digxion-Avidin was used to bind the probe and at last the tissue sections were stained with DAB. The PCR primer is as follows: AAGAGGATTCGGGCCTCTCT, CCCTGACTGGTAGCCACTTG.

\section{MTT assay}

MTT assay was performed to determine the effect of glipizide on cell proliferation. Briefly, cells were introduced into 96 well plates and then treated with various dose of glipizide. After incubation for 48-72 h, $10 \mu \mathrm{L}$ of MTT reagent was added to each well. The plates were incubated at $37^{\circ} \mathrm{C}$ for $4 \mathrm{~h}$ and then the supernatant removed. The resultant formazan crystals were dissolved using $150 \mu \mathrm{L}$ of DMSO (Sigma). The absorption was read at $570 \mathrm{~nm}$ through a spectrophotometer. The assay was performed in triplicate.

\section{Tube formation assay}

The effect of glipizide on vascular tube formation was determined using HUVEC cells. The cells $\left(1.5 \times 10^{5}\right.$ cells $/ \mathrm{mL}$ ) in suspended EBM were uniformly spread onto growth factor-reduced matrigel in 96-well chamber. After the plates were incubated for $5 \mathrm{~h}$ at $37^{\circ} \mathrm{C}$, the presence of vascular tubes was photographed using a phase contrast inverted microscope. The length of the tubes was measured using image analysis software.

\section{Cell migration assay}

Boyden Chamber Transwells were used to evaluate cell migration ability. HUVEC cells were maintained in serum-free media for $5 \mathrm{~h}$. Cell migration was examined as a standard protocol. Briefly, a porous polycarbonate membrane $(8-\mu \mathrm{m}$ pore diameter; cat. no. PFB8, Neuro Probe, ) was coated with $1 \%$ gelatin (Sigma) for $1 \mathrm{~h}$ and sterilized. HUVEC cells were harvested and suspended in serum-free EBM medium containing different concentrations of glipizide. $50 \mu \mathrm{L}$ of cells $\left(2.5 \times 10^{4}\right.$ cells $)$ were introduced to the upper chamber of the transwell and the lower chambers were added culture medium containing $20 \%$ FBS plus various growth factors (SDF1, HB-EGF, VEGF and HGFApoG2). The polycarbonate membrane was inserted between the upper and lower chambers. After the cells in the Boyden Chamber were incubated at $37^{\circ} \mathrm{C}$ for $12 \mathrm{~h}$, the cells were then removed from the upper side of the membrane by using a cotton swab. And then the cells were stained with $1 \%$ crystal violet for $3 \mathrm{~h}$ after fixed in $4 \%$ paraformaldehyde overnight. The cells were counted using a microscope at $4 \times$ magnification.

\section{Quantitative real-time PCR}

Total RNA was extracted from HUVEC cells that have been treated with glipizide or DMSO (control). The PCR array was performed using a TaqMan-based qPCR assay kit (cat. no. PAMM-024A; SA Biosciences). An ABI PRISM 7000HT Sequence Detection System (Applied Biosystems) was used for all qPCR analysis. Triplicate qPCR reactions were performed for each of the samples analyzed.

\section{Western blotting}

HUVECs cells were harvested and suspended in lysis buffer to extract whole-cell protein. $60 \mu \mathrm{g}$ of total protein was then separated by SDS-PAGE $(10 \%$ polyacrylamide gel) and transferred onto nitrocellulose membranes. Antibody against NPRA was purchased from Santa Cruz, and the immunoblotting was performed according to manufacturer's instructions.

\section{Over-expression and silencing NPRA}

Full length NPRA cDNA or short hairpin RNA (shRNA) constructs that targeted the NPRA transcript were purchased from Open Biosystems. Cells were transfected with these constructs along with plasmid carrying the green fluorescence protein (GFP) marker. The efficacy of these constructs in over-expressing and silencing NPRA was validated by immunoblotting using NPRA antibody. 


\section{Statistical analysis}

Data analyses and drawing of statistical charts were performed using a Graphpad Prism 5 software package (Graphpad Software, CA). The results were statistically analyzed using a two-tailed Student's t-test, as the prerequisites (independence and normal distribution) were satisfied. Data gathered from immunohistochemistry, tumor volumes and tissue weights of compared between glipizide-treated and control specimens. Differences between the groups were considered significant at $p<0.05$.

\section{Authors' Contributions}

Conception and design: C. Qi, Q. Zhou, Y. Yang, B. Li, Y. Ye, J. Li, Y. Ding, H. Wang, J. Wang, X. He, X. Yang, L. Wang

Development of methodology: C. Qi, Q. Zhou, Y. Yang, B. Li, Y. Ye, J. Li, Y. Ding, H. Wang, J. Wang, X. $\mathrm{He}, \mathrm{X}$. Yang, L. Wang

Acquisition of data (provided animals, acquired and managed patients, provided facilities, etc.): C. Qi, Q. Zhou, Y. Yang, B. Li, Y. Ye, J. Li, Y. Ding, H. Wang, J. Wang, X. He, X. Yang

Analysis and interpretation of data (e.g., statistical analysis, biostatistics, computational analysis): C. Qi, Q. Zhou, Y. Yang, B. Li, Y. Ye, J. Li, Y. Ding, H. Wang, J. Wang, X. He, X. Yang, L. Wang

Writing, review, and/or revision of the manuscript: C. Qi, L. Cao, K.K.H. Lee, J. Zhou, X. Yang, L. Wang

Administrative, technical, or material support (i.e., reporting or organizing data, constructing databases): $\mathrm{C}$. Qi, Q. Zhou, Y. Yang, B. Li, Y. Ye, J. Li, Y. Ding, H. Wang, J. Wang, X. He, X. Yang, L. Wang

Study supervision: C. Qi, Q. Zhang, T. Lan, W. Li, $\mathrm{X}$. Song, X. Yang, L.Wang

\section{ACKNOWLEDGEMENTS}

The authors thank Jianguo Geng and Yanqing Lin for preliminary experiments and technical assistance. This work was supported by grants from Ministry of Science and Technology of China (National Basic Research Program of China 2010CB529703 to Lijing Wang), and National Science Foundation of China (31271455, 31471290 to Lijing Wang, 3117132 to Liu Cao, 31200896 to Qianqian Zhang), the key project of the National Natural Science Foundation (81130042 to Liu Cao), and Science and Technology Planning Project of Guangdong Province (2013B060300022 to Cuiling Qi).

\section{REFERENCES}

1. Hobson B, Denekamp J. Endothelial proliferation in tumours and normal tissues: continuous labelling studies.
Br J Cancer. 1984;49:405-13.

2. Hanahan D, Folkman J. Patterns and emerging mechanisms of the angiogenic switch during tumorigenesis. Cell. 1996;86:353-64.

3. Bergers G, Hanahan D. Modes of resistance to antiangiogenic therapy. Nat Rev Cancer. 2008;8:592-603.

4. Ribatti D, Vacca A, Roncali L, Dammacco F. The chick embryo chorioallantoic membrane as a model for in vivo research on angiogenesis. Int J Dev Biol. 1996;40:1189-97.

5. Tufan AC, Satrioglutufan NL. The chick embryo chorioallantoic membrane as a model system for the study of tumor angiogenesis, invasion and development of antiangiogenic agents. Curr Cancer Drug Tar. 2005;5:249-66.

6. Mizuno CS, Chittiboyina AG, Kurtz TW, Pershadsingh HA, Avery MA. Type 2 diabetes and oral antihyperglycemic drugs. Current medicinal chemistry. 2008;15:61-74.

7. Riddle MC. Oral pharmacologic management of type 2 diabetes. American family physician. 1999;60:2613-20.

8. Skyler JS. Diabetes mellitus: pathogenesis and treatment strategies. Journal of medicinal chemistry. 2004;47:4113-7.

9. Rodriguez C, Patel AV, Mondul AM, Jacobs EJ, Thun MJ, Calle EE. Diabetes and risk of prostate cancer in a prospective cohort of US men. Am J Epidemiol. 2005; 161:147-52.

10. Seow A, Yuan JM, Koh WP, Lee HP, Yu MC. Diabetes mellitus and risk of colorectal cancer in the Singapore Chinese Health Study. Journal of the National Cancer Institute. 2006;98:135-8.

11. Huxley R, Ansary-Moghaddam A, Berrington de Gonzalez A, Barzi F, Woodward M. Type-II diabetes and pancreatic cancer: a meta-analysis of 36 studies. British journal of cancer. 2005;92:2076-83.

12. Inoue $\mathrm{M}$, Iwasaki $\mathrm{M}$, Otani $\mathrm{T}$, Sasazuki $\mathrm{S}$, Noda $\mathrm{M}$, Tsugane S. Diabetes mellitus and the risk of cancer: results from a large-scale population-based cohort study in Japan. Archives of internal medicine. 2006;166:1871-7.

13. Rousseau MC, Parent ME, Pollak MN, Siemiatycki J. Diabetes mellitus and cancer risk in a population-based case-control study among men from Montreal, Canada. International journal of cancer. 2006;118:2105-9.

14. Davila JA, Morgan RO, Shaib Y, McGlynn KA, El-Serag HB. Diabetes increases the risk of hepatocellular carcinoma in the United States: a population based case control study. Gut. 2005;54:533-9.

15. Yang X, Shang H, Katz A, Li X. A modified aggregate culture for chondrogenesis of human adipose-derived stem cells genetically modified with growth and differentiation factor 5. Biores Open Access. 2013;2:258-65.

16. Bliss DP, Jr., Battey JF, Linnoila RI, Birrer MJ, Gazdar $\mathrm{AF}$, Johnson BE. Expression of the atrial natriuretic factor gene in small cell lung cancer tumors and tumor cell lines. Journal of the National Cancer Institute. 1990;82:305-10.

17. Wang X, Raulji P, Mohapatra SS, Patel R, Hellermann G, Kong X, Vera PL, Meyer-Siegler KL, Coppola D, 
Mohapatra S. Natriuretic peptide receptor a as a novel target for prostate cancer. Molecular cancer. 2011;10:10-56.

18. Kong X, Wang X, Xu W, Behera S, Hellermann G, Kumar A, Lockey RF, Mohapatra S, Mohapatra SS. Natriuretic peptide receptor a as a novel anticancer target. Cancer research. 2008;68:249-56.

19. Mallela J, Ravi S, Jean Louis F, Mulaney B, Cheung M, Sree Garapati U, Chinnasamy V, Wang C, Nagaraj S, Mohapatra SS, Mohapatra S. Natriuretic Peptide receptor a signaling regulates stem cell recruitment and angiogenesis: a model to study linkage between inflammation and tumorigenesis. Stem cells. 2013;31:1321-9.

20. Guy CT, Cardiff RD, Muller WJ. Induction of mammary tumors by expression of polyomavirus middle $\mathrm{T}$ oncogene: a transgenic mouse model for metastatic disease. Molecular and cellular biology. 1992;12:954-61.

21. Sabrane K, Kruse MN, Fabritz L, Zetsche B, Mitko D, Skryabin BV, Zwiener M, Baba HA, Yanagisawa M, Kuhn M. Vascular endothelium is critically involved in the hypotensive and hypovolemic actions of atrial natriuretic peptide. J Clin Invest. 2005;115:1666-74.

22. McKay MK, Huxley VH. ANP increases capillary permeability to protein independent of perfusate protein composition. Am J Physiol. 1995;268:1139-48.

23. Nakayama S, Uto Y, Tanimoto K, Okuno Y, Sasaki Y, Nagasawa H, Nakata E, Arai K, Momose K, Fujita T, Hashimoto T, Okamoto Y, Asakawa Y, et al. TX-2152: a conformationally rigid and electron-rich diyne analogue of FTY720 with in vivo antiangiogenic activity. Bioorg Med Chem. 2008;16:7705-14.

24.Moiseeva O, Deschênes-Simard X, Pollak M, Ferbeyre G. Metformin, aging and cancer. Aging (Albany NY). 2013;5:330-1.

25. Apontes $\mathrm{P}$, Leontieva OV, Demidenko $\mathrm{ZN}, \mathrm{Li} \mathrm{F}$, Blagosklonny MV. Exploring long-term protection of normal human fibroblasts and epithelial cells from chemotherapy in cell culture. Oncotarget. 2011;2:222-33.

26. Cioce M, Valerio MC, Casadei L, Pulito C, Sacconi A, Mori F, Biagioni F, Manetti C, Muti P, Strano S, Blandino G. Metformin-induced metabolic reprogramming of chemoresistant ALDHbright breast cancer cells. Oncotarget. 2014;5:4129-43.

27. Cufi S, Corominas-Faja B, Vazquez-Martin A, OliverasFerraros C, Dorca J, Bosch- Barrera J, Martin-Castillo B, Menendez JA. Metformin-induced preferential killing of breast cancer initiating CD44+CD24-/low cells is sufficient to overcome primary resistance to trastuzumab in HER2+ human breast cancer xenografts. Oncotarget. 2012;3:395-8.

28. Bowker SL, Majumdar SR, Veugelers P, Johnson JA. Increased cancer-related mortality for patients with type 2 diabetes who use sulfonylureas or insulin: Response to Farooki and Schneider. Diabetes Care. 2006;29:1990-1.

29. Monami M, Balzi D, Lamanna C, Barchielli A, Masotti G, Buiatti E, Marchionni N, Mannucci E. Are sulphonylureas all the same? A cohort study on cardiovascular and cancerrelated mortality. Diabetes Metab Res Rev. 2007;23:47984.

30. Monami M, Lamanna C, Balzi D, Marchionni N, Mannucci E. Sulphonylureas and cancer: a case-control study. Acta Diabetol. 2009;46:279-84.

31. Yang X, So WY, Ma RC, Yu LW, Ko GT, Kong AP, Ng VW, Luk AO, Ozaki R, Tong PC, Chow CC, Chan JC. Use of sulphonylurea and cancer in type 2 diabetes-The Hong Kong Diabetes Registry. Diabetes Res Clin Pract. 2010;90:343-51.

32.Simonson DC1, Kourides IA, Feinglos M, Shamoon H, Fischette CT. Efficacy, safety, and dose-response characteristics of glipizide gastrointestinal therapeutic system on glycemic control and insulin secretion in NIDDM. Results of two multicenter, randomized, placebocontrolled clinical trials. The Glipizide Gastrointestinal Therapeutic System Study Group. Diabetes Care. 1997;20:597-606.

33. Menendez JA, Quirantes-Piné R, Rodríguez-Gallego E, Cufí $\mathrm{S}$, Corominas-Faja $\mathrm{B}$, Cuyàs $\mathrm{E}$, Bosch-Barrera $\mathrm{J}$, MartinCastillo B, Segura-Carretero A, Joven J. Oncobiguanides: Paracelsus' law and nonconventional routes for administering diabetobiguanides for cancer treatment. Oncotarget. 2014;5:2344-8.

34. Blagosklonny MV. A new science-business paradigm in anticancer drug development. Trends Biotechnol. 2003;21:103-6.

35. Siamblis D, Karnabatidis D, Hatjikondi O, Kalogeropoulou C, Kardamakis D, Dimopoulos J. A novel radiological approach for the experimental study of angiogenesis: angiography of the chick embryo and its chorioallantoic membrane. European journal of radiology. 1996;21:220-4.

36. Folkman J. Tumor angiogenesis: therapeutic implications. The New England journal of medicine. 1971 18;285:11826.

37. Chan T, Burggren W. Hypoxic incubation creates differential morphological effects during specific developmental critical windows in the embryo of the chicken (Gallus gallus). Respir Physiol Neurobiol. 2005;145:251-63.

38. Hagedorn M, Javerzat S, Gilges D, Meyre A, de Lafarge B, Eichmann A, Bikfalvi A. Accessing key steps of human tumor progression in vivo by using an avian embryo model. Proc Natl Acad Sci USA. 2005;102:1643-8.

39. Ozdemir BH, Akcali Z, Haberal M. Hypercholesterolemia impairs angiogenesis in patients with breast carcinoma and, therefore, lowers the risk of metastases. Am J Clin Pathol. 2004; 122:696-703. 